\begin{tabular}{|c|c|c|}
\hline $\begin{array}{c}\text { Military Technical College } \\
\text { Kobry El-Kobbah, } \\
\text { Cairo, Egypt }\end{array}$ & $\begin{array}{c}6^{\text {th }} \text { International Conference } \\
\text { on Electrical Engineering } \\
\text { ICEENG } 2008\end{array}$ \\
\hline
\end{tabular}

\title{
Optimal Transmission Congestion Management Using FACTS
}

$$
\text { By }
$$

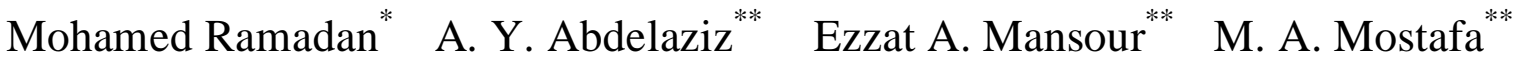

\section{Abstract:}

Electric power systems have been forced to operate to almost their capacities due to the environmental and economic constraints to build new generating plants and transmission lines. The basic requirement of power system is to meet the demand that varies continuously. The amount of power delivered by the power companies must be equal to that of consumer's need. Unfortunately nobody guarantees that unexpected things such as generator fault or line fault and line tripping would not happen. Congestion is a result of such unexpected things and it can be defined as inability of transmission system to accommodate the energy flow arising from unconstrained generator dispatch.

Due to its fast control characteristics and continuous compensation capability, Flexible AC Transmission System (FACTS) devices have been researched and adopted in power engineering area. There are so many advantages of FACTS device; it can increase dynamic stability, loading capability of lines and system security. It can also increase utilization of lowest cost generation. The key role of FACTS device is to control the power flow actively and effectively. In other words, it can transfer power flow from one line to another within its capability.

This paper presents detailed optimal transmission congestion management using control of two Flexible AC Transmission System (FACTS) controllers, namely, Thyristor Controlled Series Capacitors (TCSCs) and Thyristor Controlled Series Reactor (TCSR).

The paper focuses on the operation of the FACTS device under generator fault that may cause any other transmission lines to be overflowed. The proposed algorithm in this paper is tested on the IEEE 14 bus system and the IEEE 30 bus system. 
Proceedings of the $\boldsymbol{6}^{\text {th }}$ ICEENG Conference, 27-29 May, 2008 EE120-2

* $\quad$ Misr Petroleum Company, Cairo, Egypt

** Electrical Power \&Machine Department, Faculty of Engineering, Ain Shams University, Cairo, Egypt

Proceedings of the $6^{\text {th }}$ ICEENG Conference, 27-29 May, 2008

\section{Keywords:}

FACTS, TCSCs, TCSR, IEEE 14 bus system, IEEE 30 bus system 
Proceedings of the $\boldsymbol{6}^{\text {th }}$ ICEENG Conference, 27-29 May, 2008 EE120-3

\section{Introduction:}

The amount of electric power that can be transmitted between two locations through a transmission network is limited by security and stability constraints. Power flow in the lines and transformers should not be allowed to a level where a random event could cause the network congestion because of generator fault. When such a limit reaches, the system is said to be congested [1].

To manage the congestion in real time operations, normally, following methods are adopted:

1. Use of available resources for congestion management such as operation of FACTS controllers, rescheduling of generation based on minimum bids.

2. Provide the timely information regarding the probability of having a particular line congested and economic incentives to system users to adjust their requests and remain within the system constraints.

3. Physically curtail the transactions.

System operators always try to use first option, wherever it is possible. Physical curtailment of loads is considered as the last option for congestion management when it is impossible to wait for the system users to respond according to economic criteria. However, the second option should be developed for giving the system users sufficient information regarding the congestion probability so that they can adjust their requests for system services and avoid congestion [2].

Several optimal power flow based congestion management schemes for multiple transaction systems have been proposed. An approach using the minimum total modification to the desired transactions for relieving congestion was presented in [3].

The basic model for congestion management described in [4] was used in [5] incorporating the FACTS controllers such as TCSC and TCSR for congestion management. In [6], a sensitivity based approach for the optimal location of unified power flow controller (UPFC) was proposed for the congestion management.

Proceedings of the $6^{\text {th }}$ ICEENG Conference, 27-29 May, 2008

The collapse points are known as maximum loadability points, the voltage collapse problem can be restated as an optimization problem where the objective is to maximize certain system parameters typically associated to load levels [7-10]. 
Hence, voltage collapse techniques may also be used to compute the maximum power that can be transmitted through the transmission system, also known in the new competitive energy market as Total Transfer Capability (TTC) [11]. It is well known that shunt and series compensation can be used to increase the maximum transfer capabilities of power networks [12]. With the improvements in current voltage handling capabilities of power electric devices that have allowed for the development of FACTS, the possibility has arisen of using different types of controllers for efficient shunt and series compensation. Thus, FACTS controllers based on thyristor controllers based on thyristor controlled reactors (TCRs), such as Thyristor Controlled Series Reactors (TCSRs) and Thyristor Controlled Series Capacitors (TCSCs), are being used by several utilities to compensate their systems [13]. More recently, various types of controllers for shunt and series compensation, based on voltage source inverters (VSIs), Shunt and Series Static Synchronous Compensators (STATCOMs and SSSCs) and Unified Power Flow Controllers (UPFCs), have been proposed and developed [14].

In [15], the authors use standard voltage collapse analysis tools to study the effect in the maximum load margin of the location of a given SVC; an approximate SVC model is used for the computations. In [16], the authors use approximate SVC and TCSC models together with typical collapse computational tools and optimization techniques to determine the appropriate location and size of these controllers; dynamic simulations using more detailed models are then performed to study the effect of these controllers in the overall stability of the network.

This paper presents an optimal transmission congestion management using control of two FACTS devices, namely TCSC and TCSR. The proposed algorithm in this paper is tested and verified on the IEEE 14 bus system and the IEEE 30 bus system by using ATP simulation program.

\section{Steady state series compensator:}

There are several FACTS devices used in power system, some of them are already installed in the power system and in operation. Those devices can be categorized into 3 groups. One group in category is series compensators - TCSR, TSSC and TCSC. Another group is shunt compensators such as SVC and STACOM. The last one is combined compensators like UPFC and IPFC.

Among those compensators, series compensators are adopted in this paper because it shows highly cost efficient characteristics in controlling the active power flow [17].

Proceedings of the $6^{\text {th }}$ ICEENG Conference, 27-29 May, 2008

Fig. (1) shows the common structure of series compensator which consists of the series compensating capacitor shunted by a TCR (Thyristor Controlled Reactor). 
In steady state, it has similar characteristics of parallel LC circuit but continuously variable reactive impedance, controllable by the delay angle $\alpha$.

The equivalent impedance to the fundamental frequency at steady state can be expressed like equation (1).

The steady-state equivalent model of all series compensator is presented on Fig. (2) based on the above description.

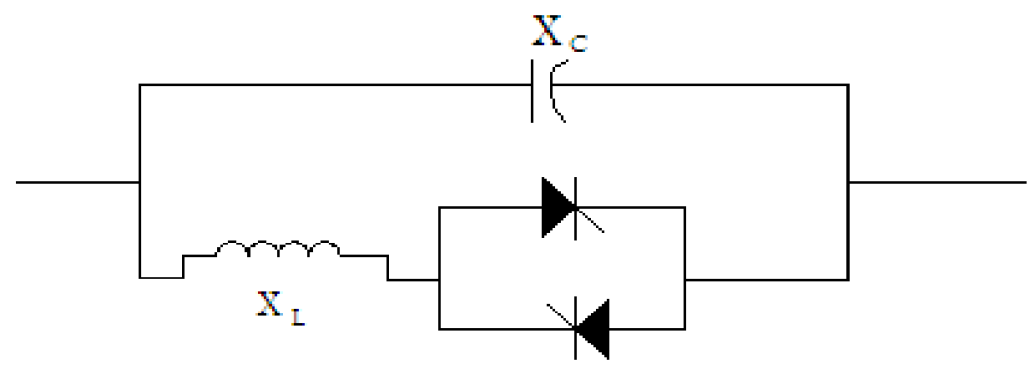

Fig. (1): Common structure of series compensator

$$
\begin{aligned}
X_{\mathrm{tcsc}}= & \left(\mathrm{X}_{\mathrm{C}} \cdot \mathrm{X}_{\mathrm{V}}\right) /\left(\mathrm{X}_{\mathrm{C}}-\mathrm{X}_{\mathrm{V}}\right) \\
= & \left(\mathrm{X}_{\mathrm{C}} \cdot \mathrm{X}_{\mathrm{L}}\right) /\left[\left(\mathrm{X}_{\mathrm{C}} / \pi((2 \pi-\alpha)+\sin 2 \alpha)\right)-\mathrm{X}_{\mathrm{L}}\right] \\
\text { where } & \mathrm{X}_{\mathrm{tcsc}}: \text { reactance of TCSC } \\
& \mathrm{X}_{\mathrm{C}}: \text { reactance of reactor } \\
& \mathrm{X}_{\mathrm{L}}: \text { reactance of series capacitor } \\
& \mathrm{X}_{\mathrm{V}}=\mathrm{X}_{\mathrm{L}} \cdot \pi /(\delta+\sin 2 \alpha) \\
& \delta=2(\pi-\alpha)
\end{aligned}
$$

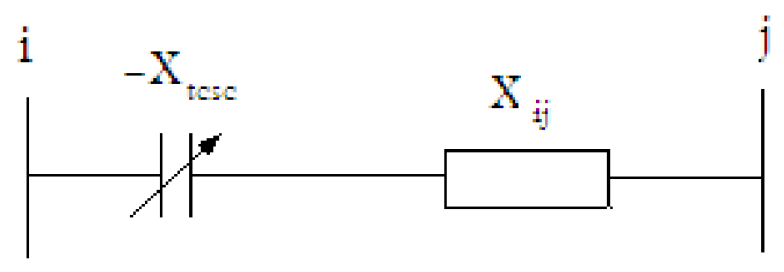

Fig. (2): Steady-state equivalent circuit of series compansator 


\section{Simulation Results:}

The ATP (Alternative Transient Program) is used in this paper. Four kinds of simulations have been done in this paper.

The first one is the power flow calculation without congestion.

The second simulation shows the lines which have been congested due to generator faults.

The third simulation shows the TCSC operation in case of line congestion after a generator fault. Finally, the last simulation shows TCSR operation in case of line congestion after a generator fault.

\subsection{Systems under study:}

\subsubsection{The IEEE 14 bus system:}

Fig.(3) shows a single line diagram for the IEEE 14 bus system under study. Fig.(4) shows the voltage from bus 1 to bus 5 without any congestion. Fig.(5) shows the voltage from bus 1 to bus 5 with congestion due to a fault at generator connected to bus 1 and the voltage is decreased.

Fig.(6) shows the voltage from bus 1 to bus 5 with congestion by using Thyristor Controlled Series Capacitor (TCSC) at bus 1 and the voltage is increased to the normal state. Fig.(7) shows the voltage from bus 1 to bus 5 with congestion by using Thyristor Controlled Series Reactor (TCSR) at bus 1 and the voltage is increased to the normal state.

Fig.(8) shows the voltage from bus 2 to bus 4 without any congestion. Fig.(9) shows the voltage from bus 2 to bus 4 with congestion due to a fault of generator connected to bus 2 and the voltage is decreased. Fig.(10) shows the voltage from bus 2 to bus 4 with congestion by using Thyristor Controlled Series Capacitor (TCSC) at bus 2 and the voltage is increased to the normal state. Fig.(11) shows the voltage from bus 2 to bus 4 with congestion by using Thyristor Controlled Series Reactor (TCSR) at bus 2 and the voltage is increased to the normal state.

Fig.(12) shows the voltage from bus 3 to bus 4 without any congestion. Fig.(13) shows the voltage from bus 3 to bus 4 with congestion due to a fault of generator connected to bus 3 and the voltage is decreased. Fig.(14) shows the voltage from bus 3 to bus 4 with congestion by using Thyristor Controlled Series Capacitor (TCSC) at bus 3 and the voltage is increased to the normal state. Fig.(15) shows the voltage from bus 3 to bus 4 with congestion by using Thyristor Controlled Series Reactor (TCSR) at bus 3 and the voltage is increased very close (near) to the normal state. 
Proceedings of the $\boldsymbol{6}^{\text {th }}$ ICEENG Conference, 27-29 May, 2008 EE120-7

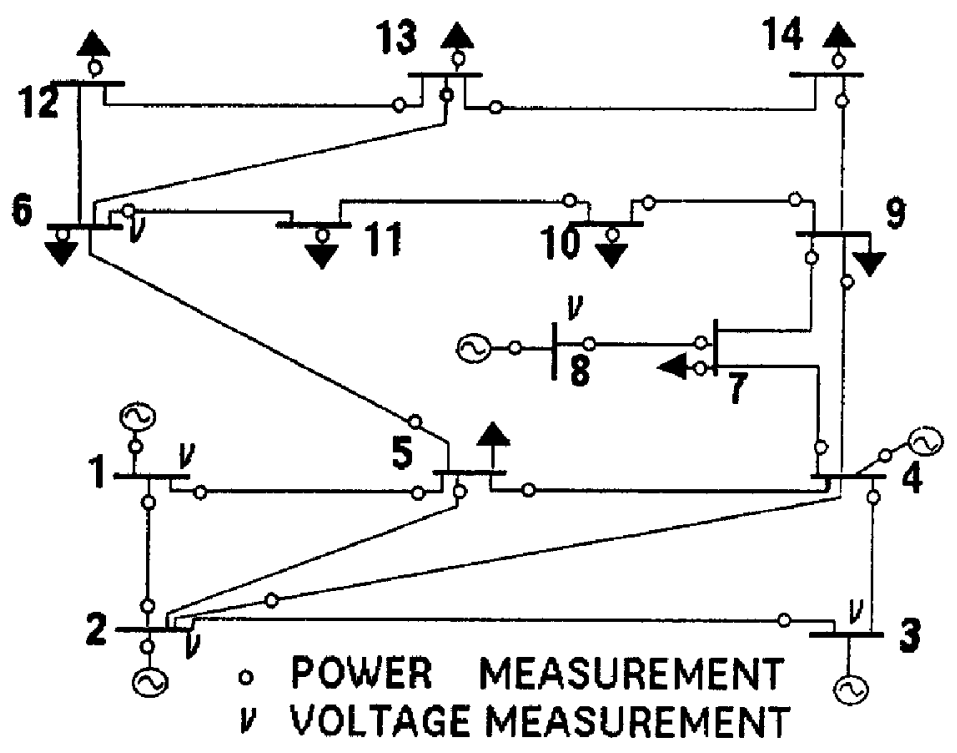

Fig. (3): The IEEE 14 bus system

14 bus system

voltage from bus 1 to bus 5

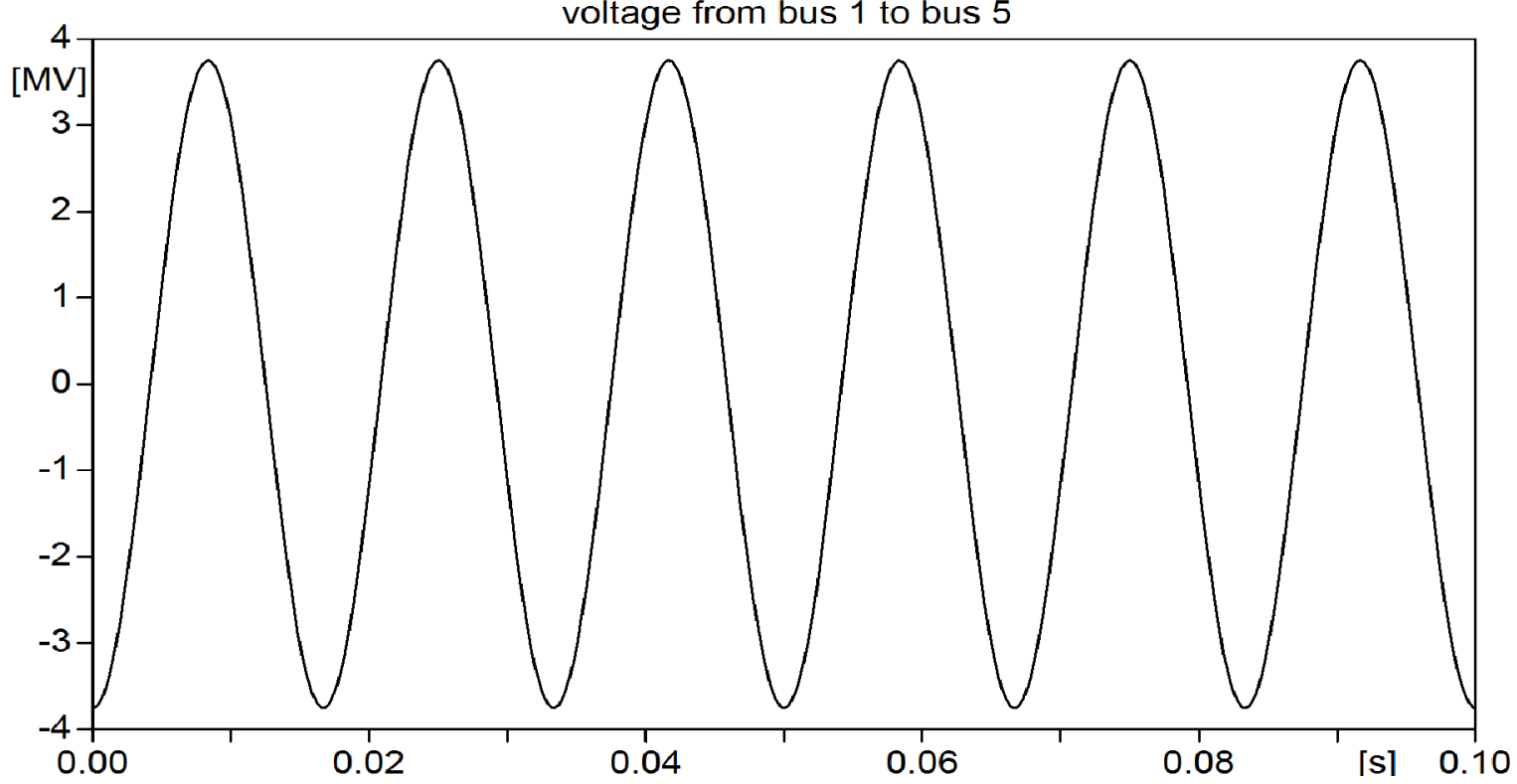

Fig. (4): The voltage from bus 1 to bus 5 without any congestion 
Proceedings of the $\boldsymbol{6}^{\text {th }}$ ICEENG Conference, 27-29 May, 2008 EE120-8

Proceedings of the $6^{\text {th }}$ ICEENG Conference, 27-29 May, 2008

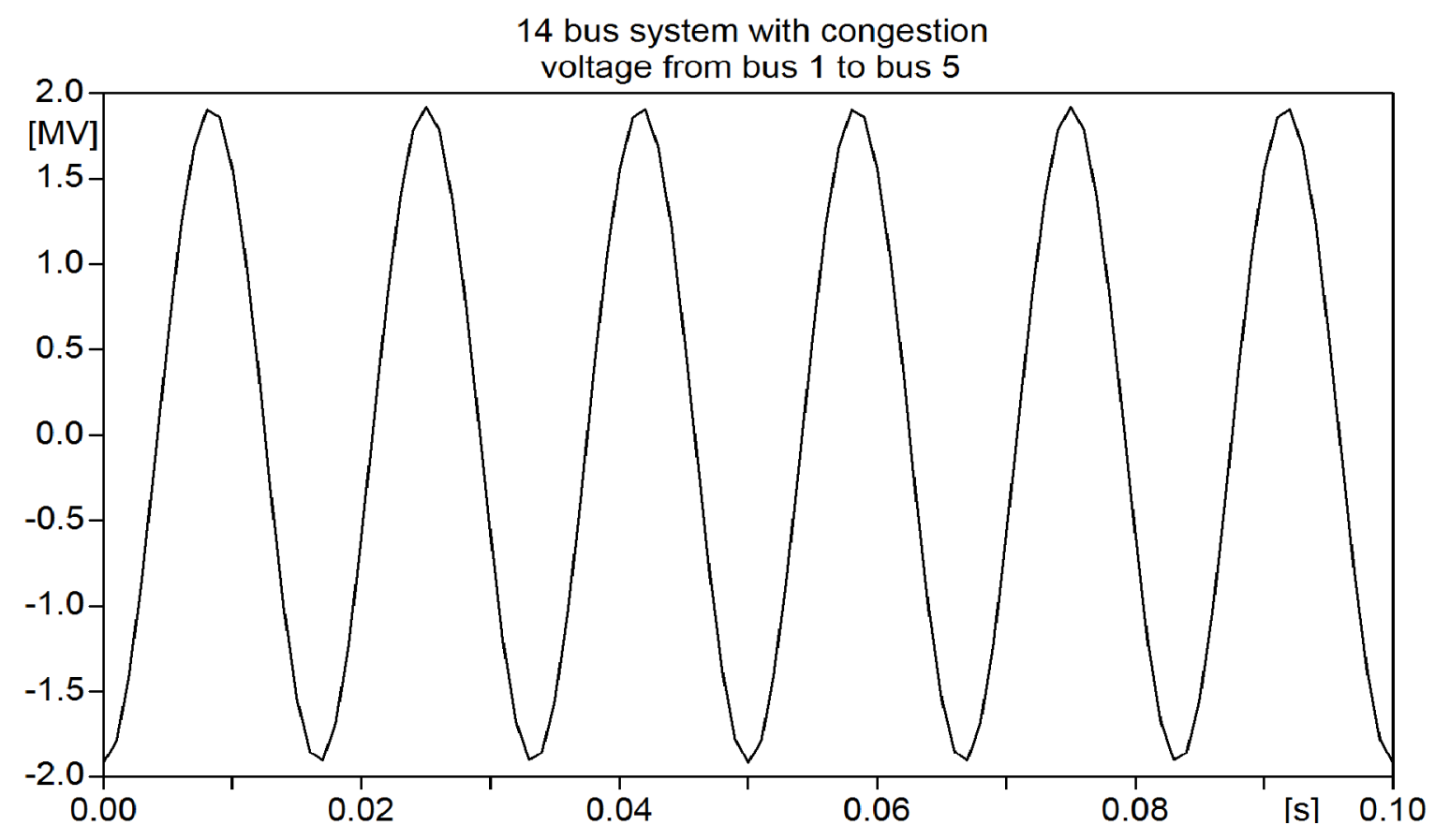

Fig. (5): The voltage from bus 1 to bus 5 with congestion

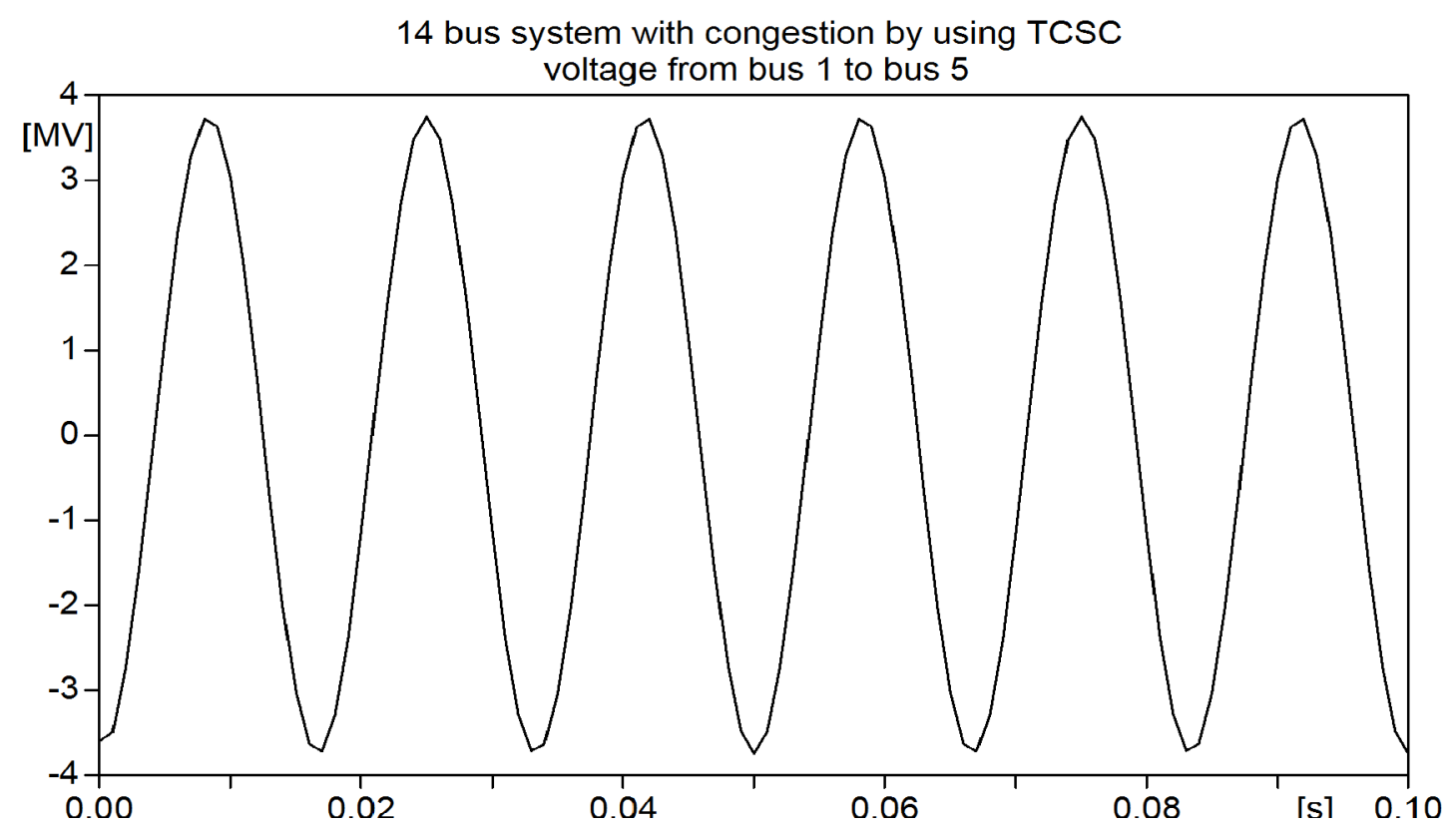

Fig. (6): The voltage from bus 1 to bus 5 with congestion by using (TCSC) at bus 1 
Proceedings of the $\boldsymbol{6}^{\text {th }}$ ICEENG Conference, 27-29 May, 2008 EE120-9

Proceedings of the $6^{\text {th }}$ ICEENG Conference, 27-29 May, 2008

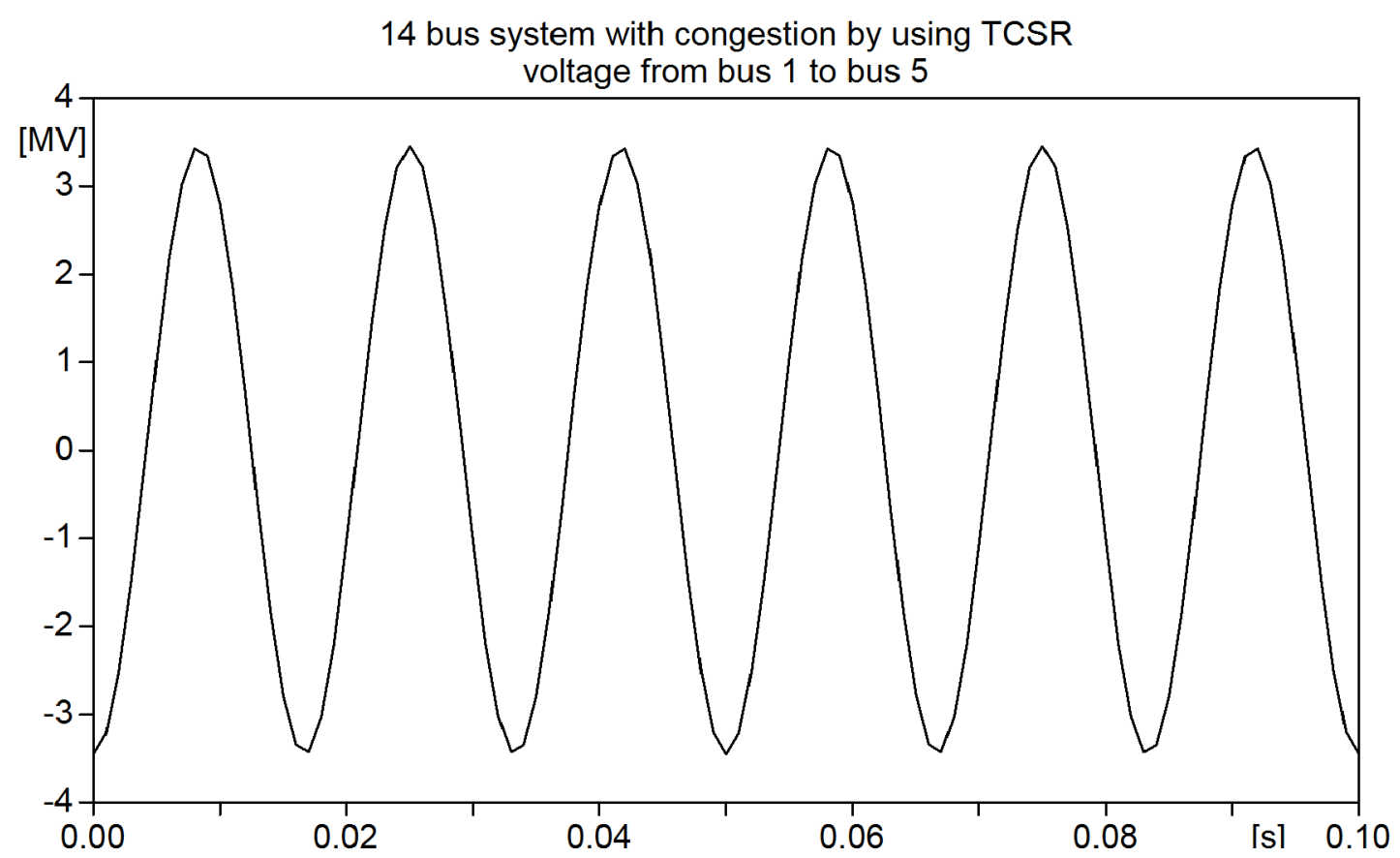

Fig. (7): The voltage from bus 1 to bus 5 with congestion by using (TCSR) at bus 1

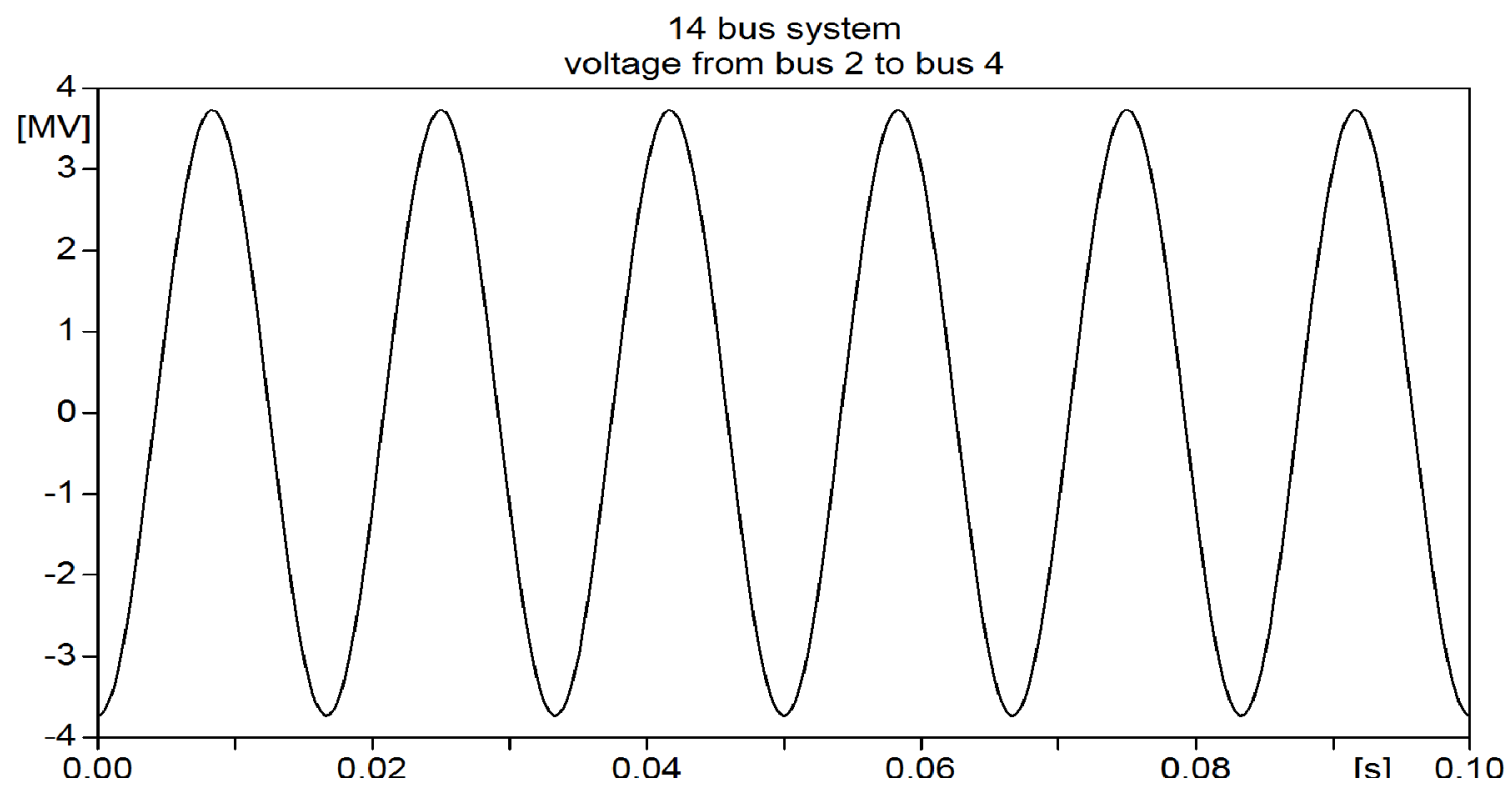

Fig. (8): The voltage from bus 2 to bus 4 without any congestion 


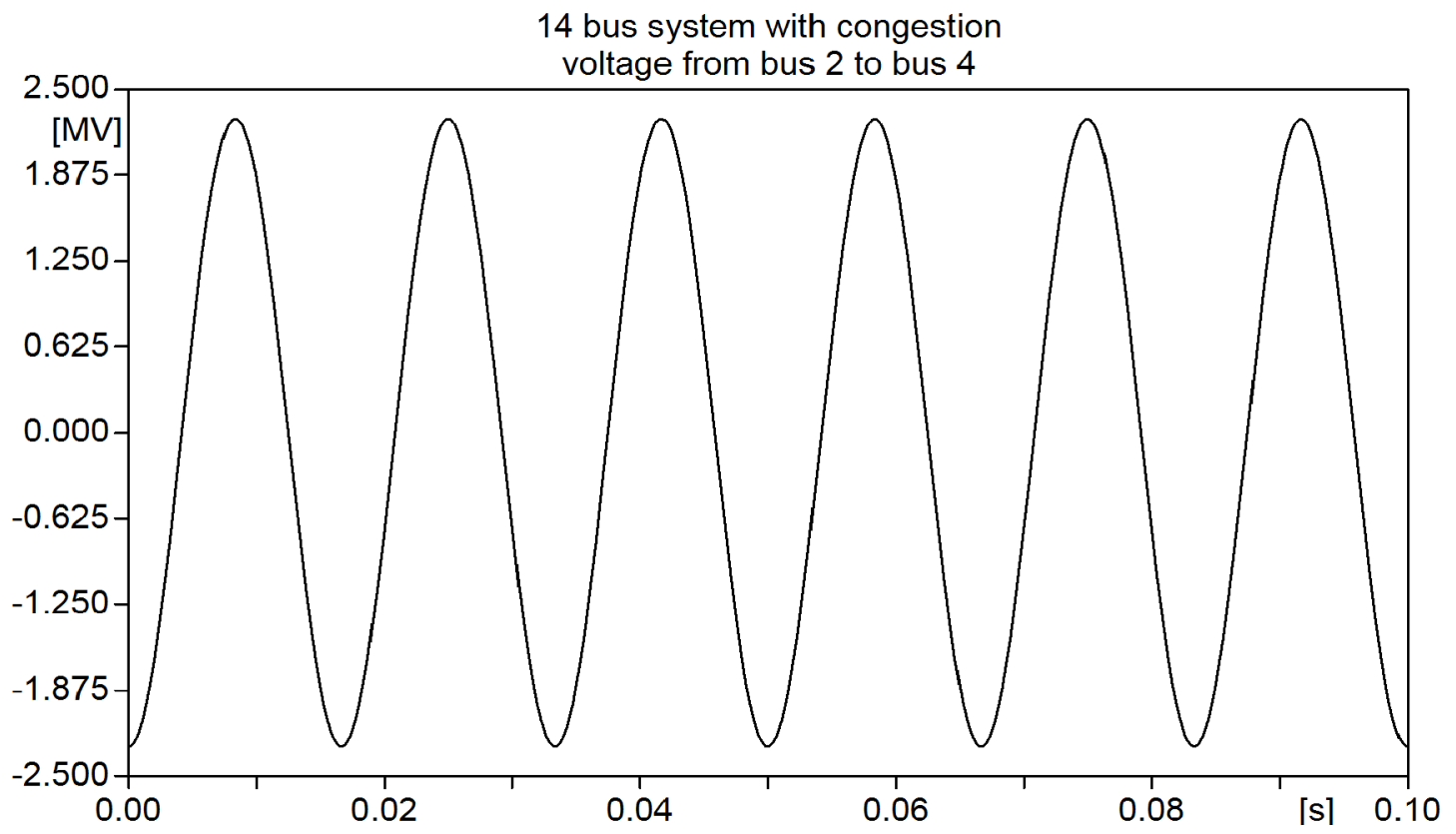

Fig. (9): The voltage from bus 2 to bus 4 with congestion

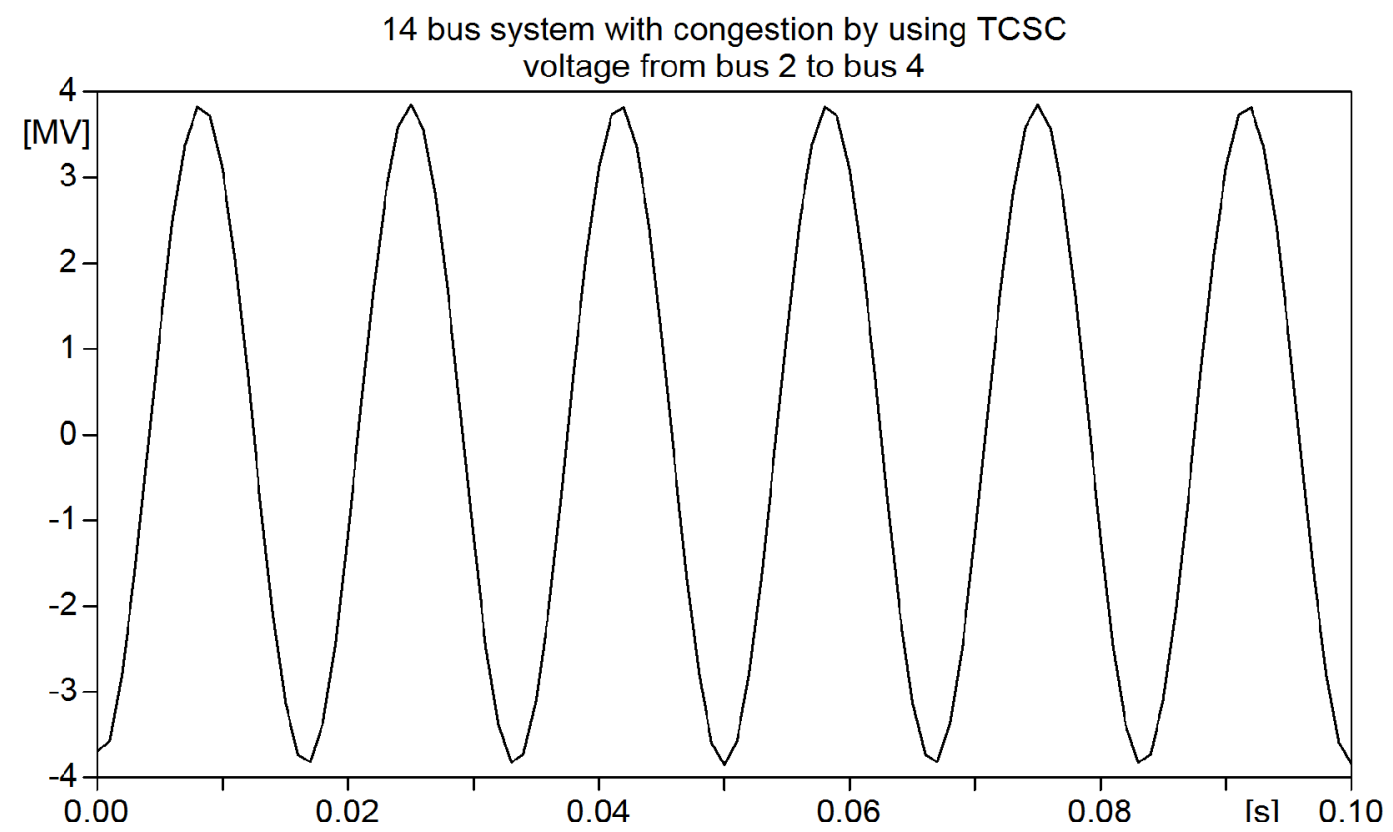


Proceedings of the $\boldsymbol{6}^{\text {th }}$ ICEENG Conference, 27-29 May, 2008 EE120-11

Fig. (10): The voltage from bus 2 to bus 4 with congestion by using (TCSC) at bus 2

Proceedings of the $6^{\text {th }}$ ICEENG Conference, 27-29 May, 2008

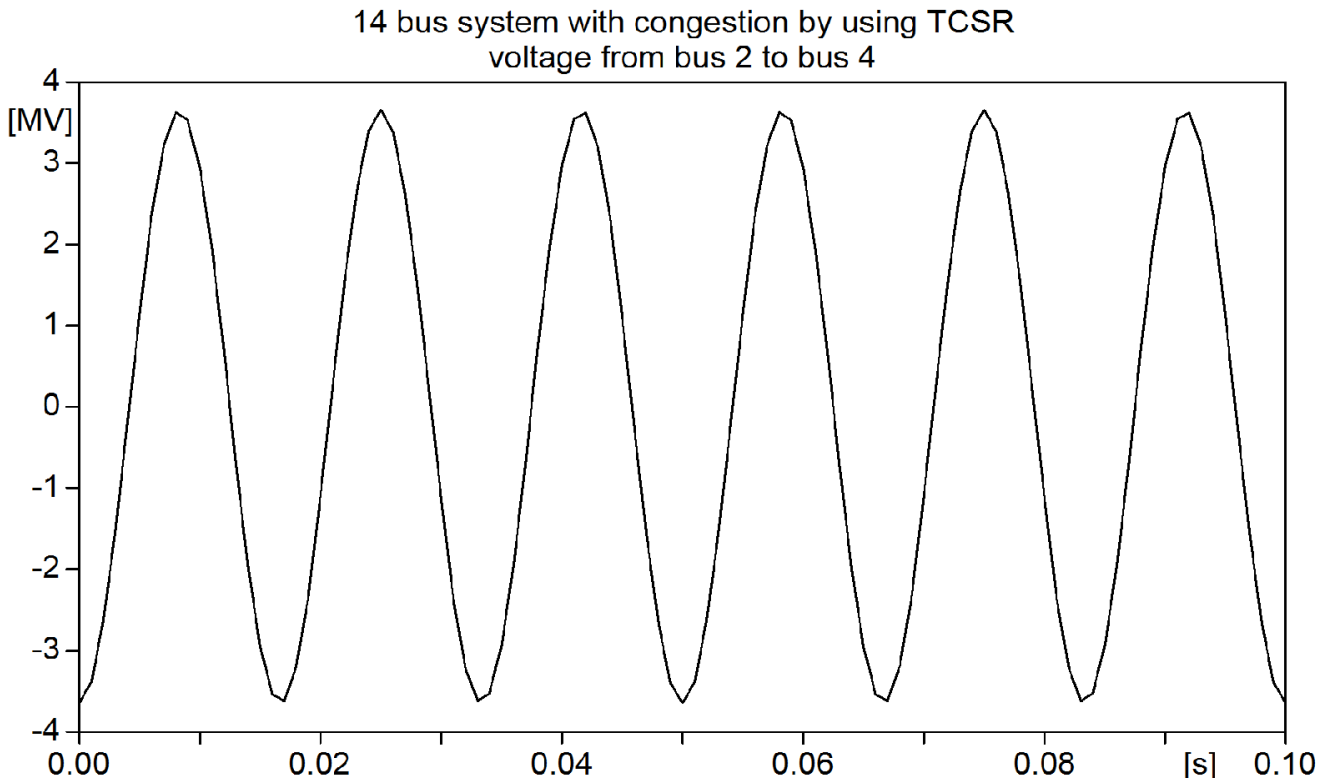

Fig. (11): The voltage from bus 2 to bus 4 with congestion by using (TCSR) at bus 2

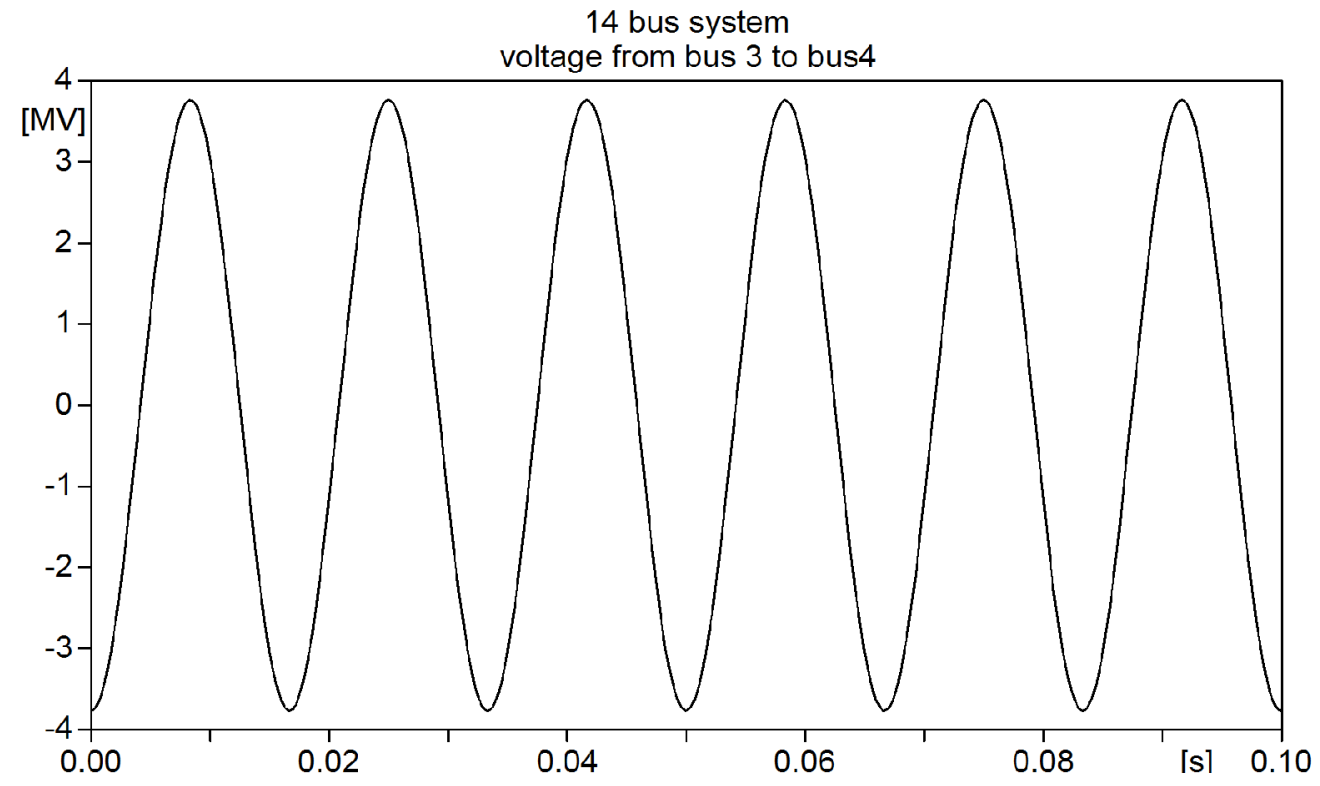


Proceedings of the $\boldsymbol{6}^{\text {th }}$ ICEENG Conference, 27-29 May, 2008 EE120-12

Fig. (12): The voltage from bus 3 to bus 4 without any congestion

Proceedings of the $6^{\text {th }}$ ICEENG Conference, 27-29 May, 2008

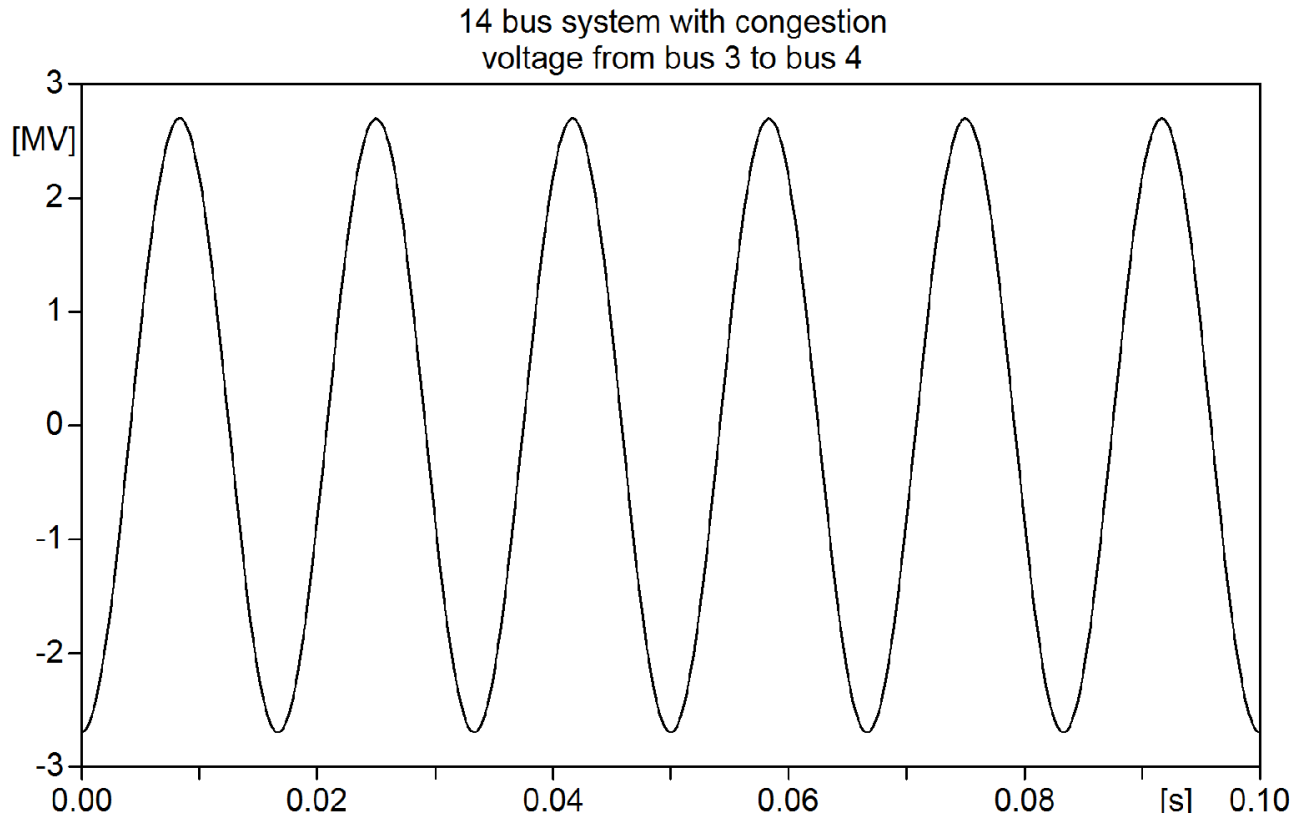

Fig. (13): The voltage from bus 3 to bus 4 with congestion

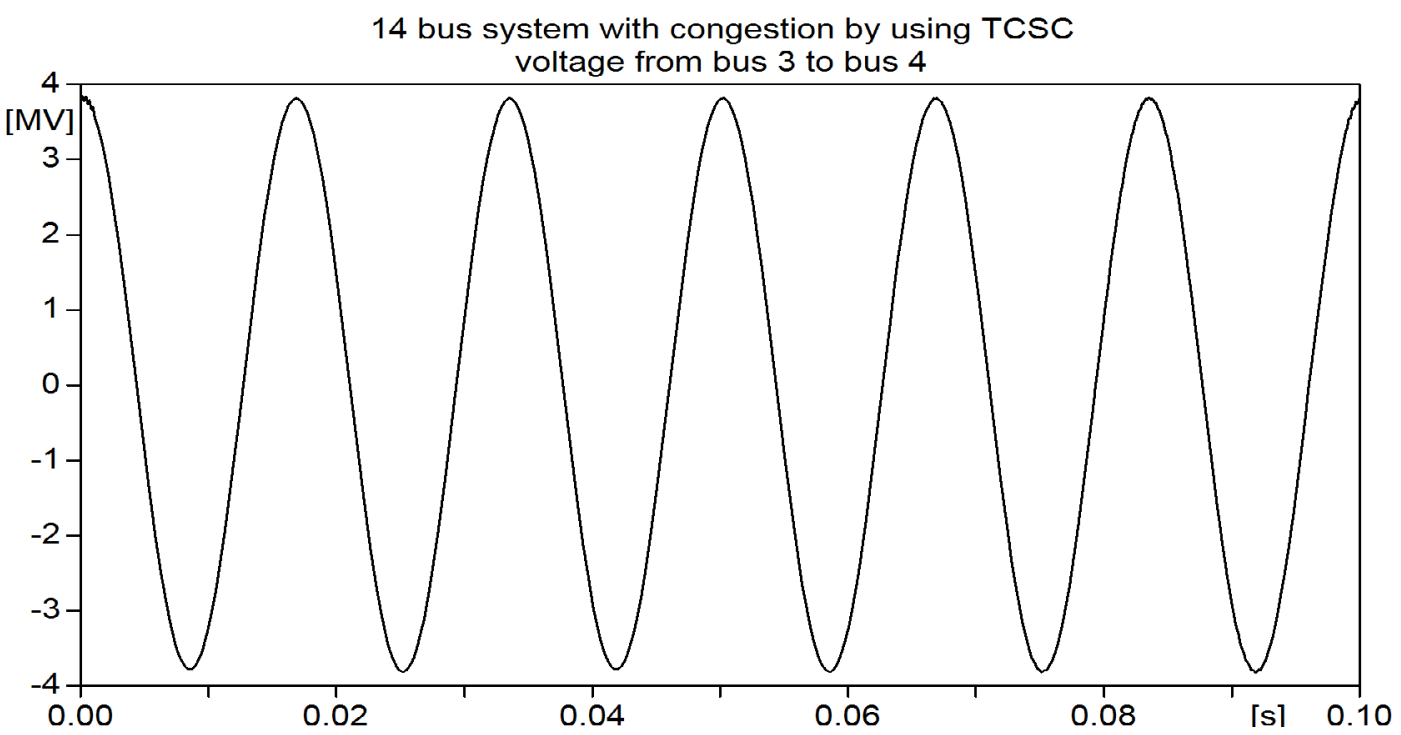


Fig. (14): The voltage from bus 3 to bus 4 with congestion by using (TCSC) at bus 3

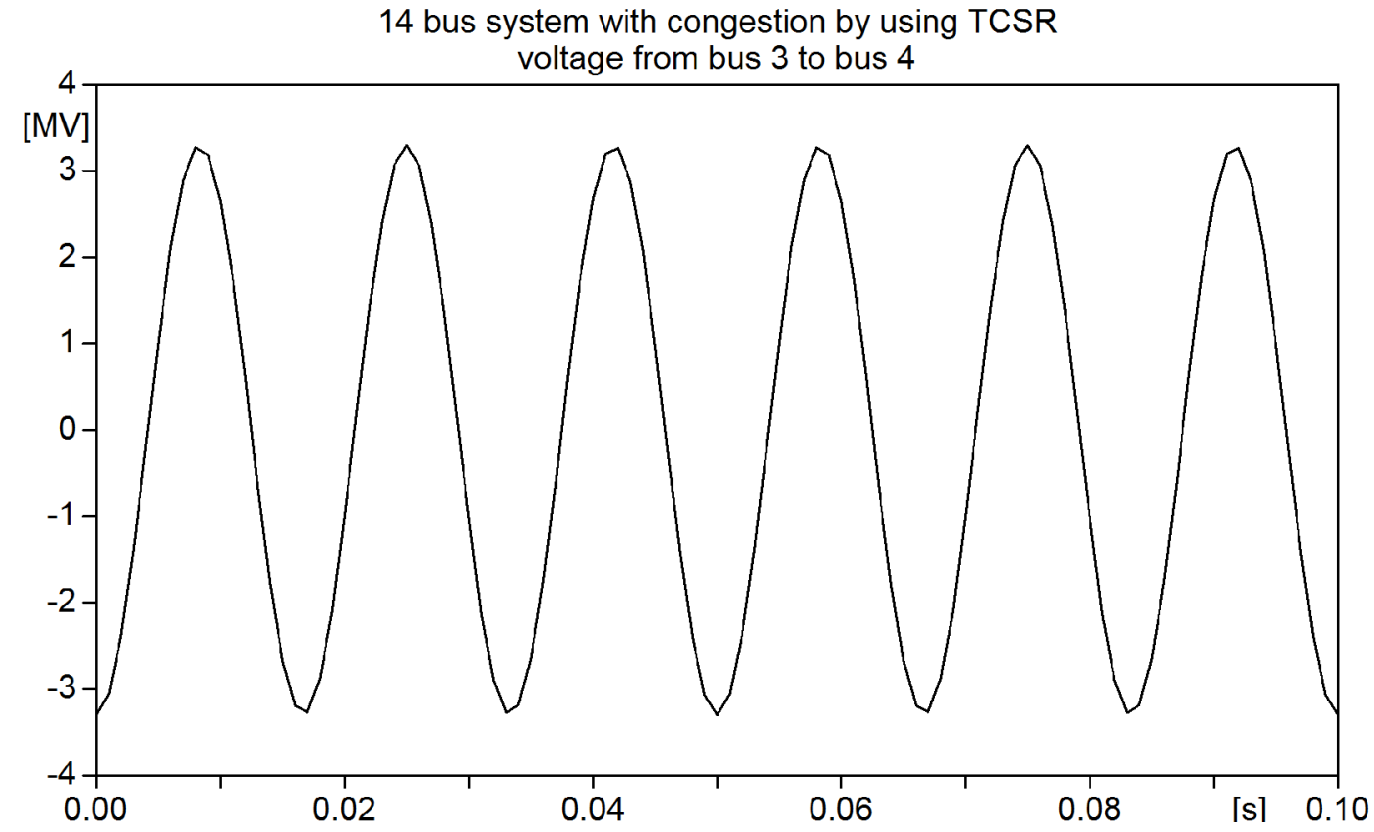

Fig. (15): The voltage from bus 3 to bus 4 with congestion by using (TCSR) at bus 3

\subsubsection{The IEEE 30 bus system:}

Fig.(16) shows a single line diagram for the IEEE 30 bus system under study. Fig.(17) shows the voltage from bus 1 to bus 3 without any congestion. Fig.(18) shows the voltage from bus 1 to bus 3 with congestion due to a fault at generator connected to bus 1 and it is shown that the voltage has decreased. Fig.(19) shows the voltage from bus 1 to bus 3 with congestion by using (TCSC) at bus 1 and the voltage has increased to the normal state. Fig.(20) shows the voltage from bus 1 to bus 3 with congestion by using (TCSR) at bus 1 and the voltage has increased to the normal state.

Fig.(21) shows the voltage from bus 2 to bus 4 without any congestion. Fig.(22) shows the voltage from bus 2 to bus 4 with congestion due to a fault at generator 
Proceedings of the $\boldsymbol{6}^{\text {th }}$ ICEENG Conference, 27-29 May, 2008 EE120-14

connected to bus 2 and the voltage is decreased. Fig.(23) shows the voltage from bus 2 to bus 4 with congestion by using (TCSC) at bus 2 and the voltage has increased to the normal state. Fig.(24) shows the voltage from bus 2 to bus 4 with congestion by using (TCSR) at bus 2 and the voltage has increased to the normal state.

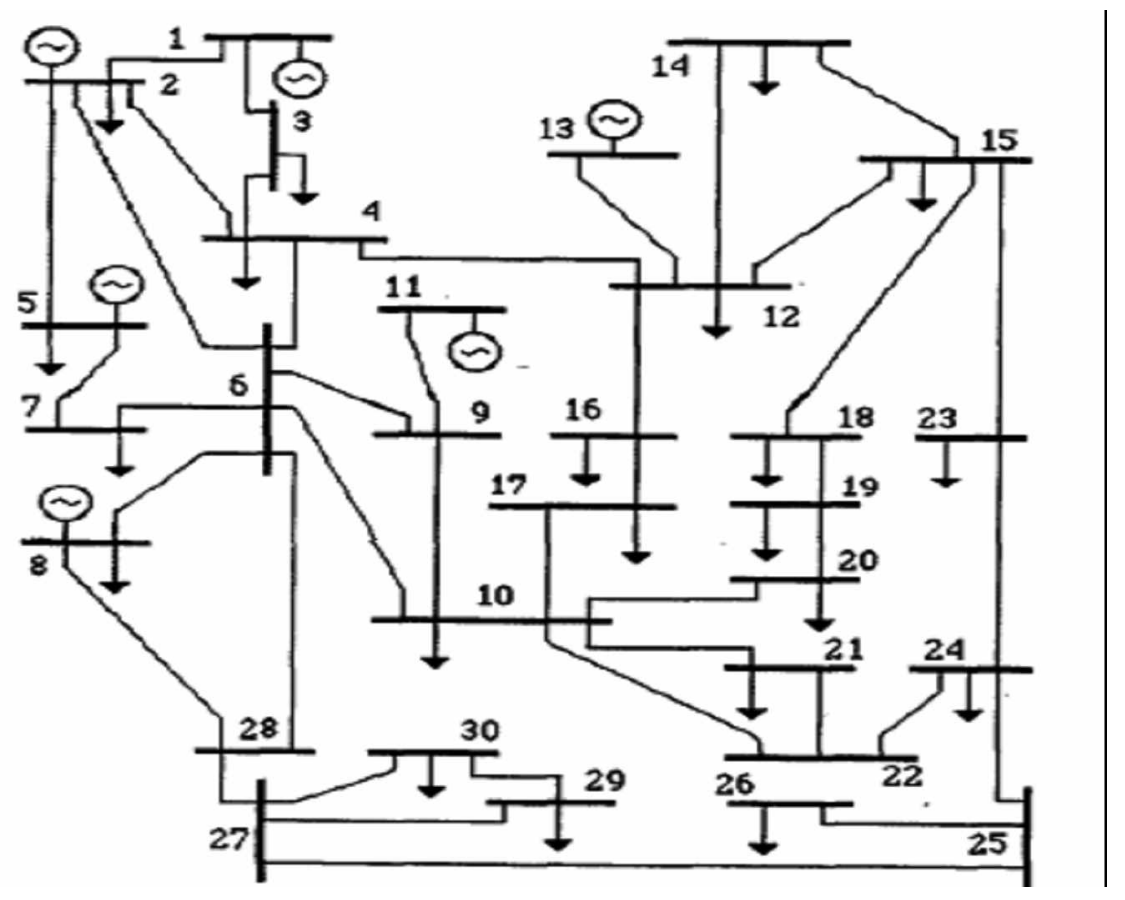

Fig. (16): The IEEE 30 bus system 
Proceedings of the $\boldsymbol{6}^{\text {th }}$ ICEENG Conference, 27-29 May, 2008 EE120-15

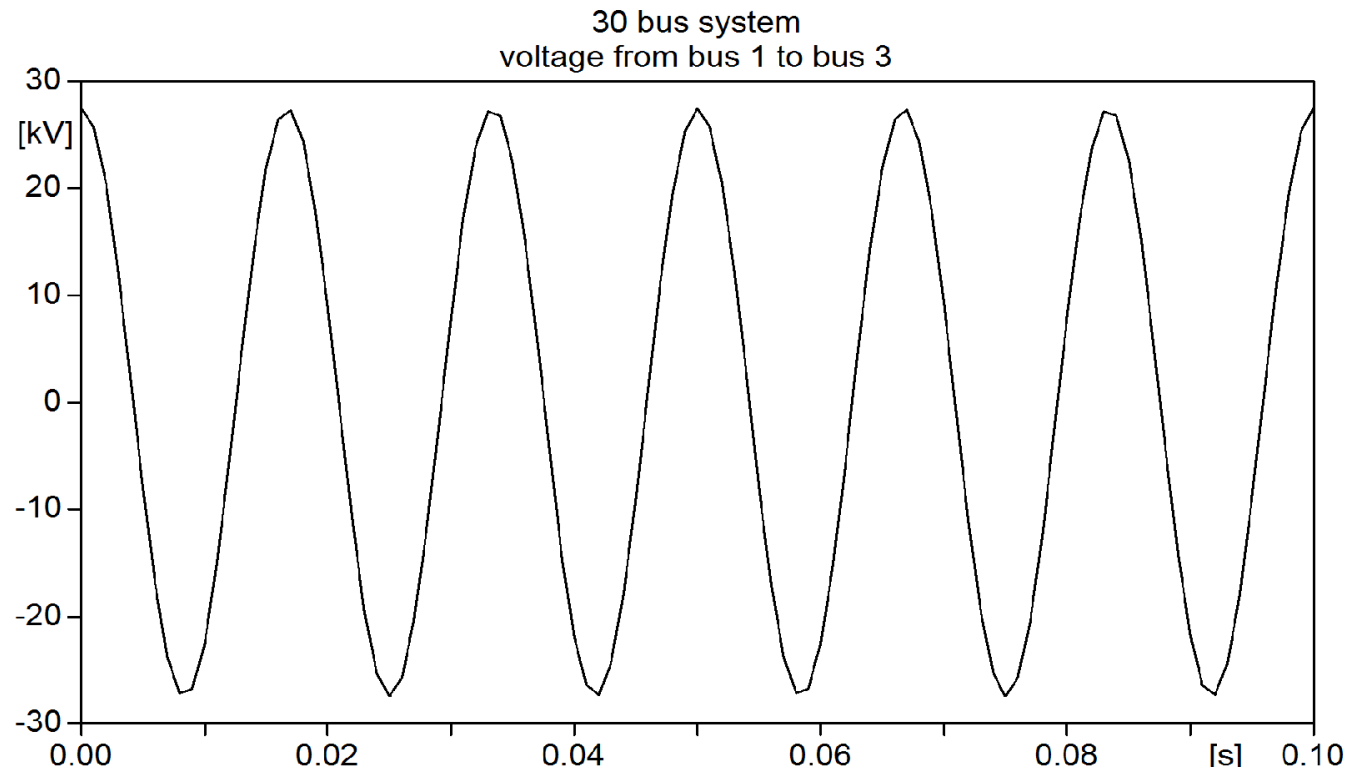

Fig. (17): The voltage from bus 1 to bus 3 without any congestion

Proceedings of the $6^{\text {th }}$ ICEENG Conference, 27-29 May, 2008

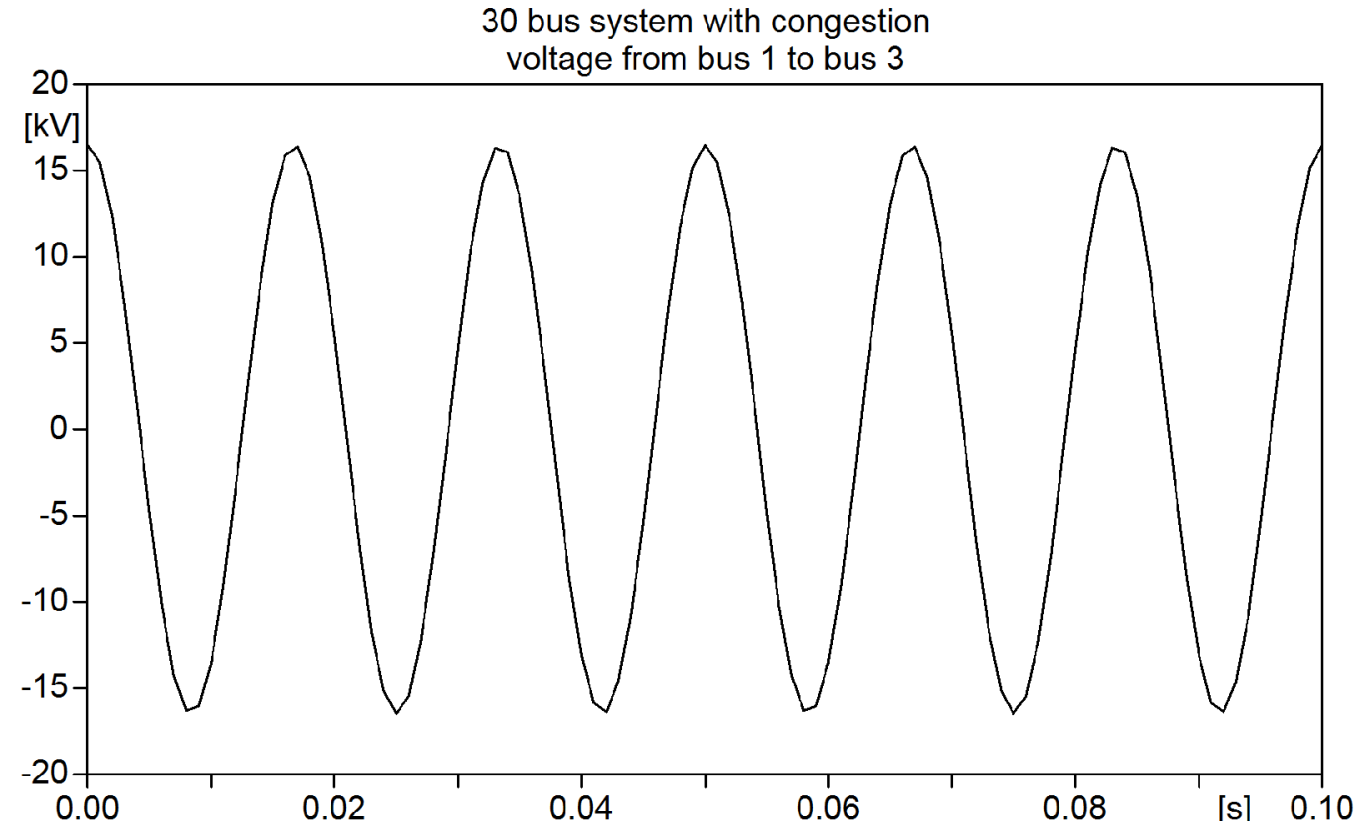

Fig. (18): The voltage from bus 1 to bus 3 with congestion 
Proceedings of the $\boldsymbol{6}^{\text {th }}$ ICEENG Conference, 27-29 May, 2008 EE120-16

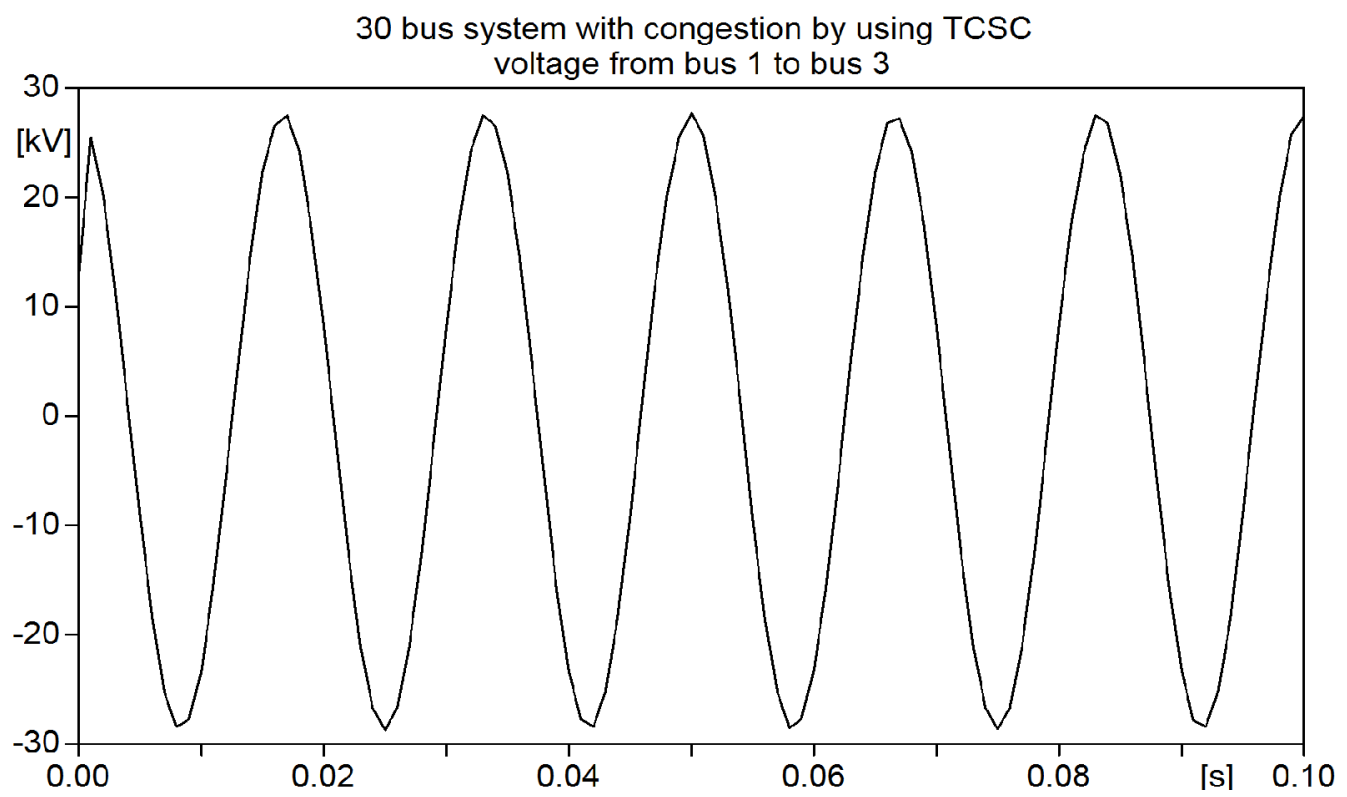

Fig. (19): The voltage from bus 1 to bus 3 with congestion by using (TCSC) at bus 1

Proceedings of the $6^{\text {th }}$ ICEENG Conference, 27-29 May, 2008

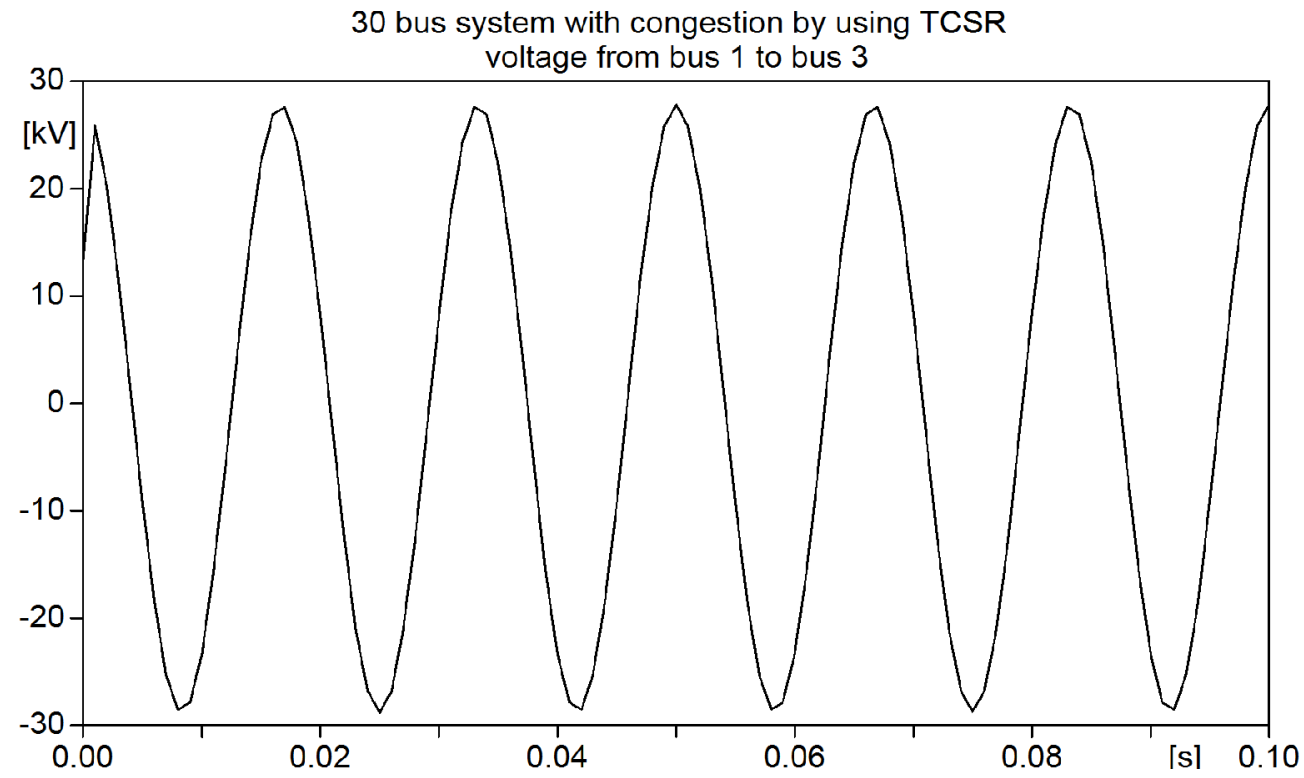

Fig. (20): The voltage from bus 1 to bus 3 with congestion by using (TCSR) at bus 1 
Proceedings of the $\boldsymbol{6}^{\text {th }}$ ICEENG Conference, 27-29 May, 2008 EE120-17

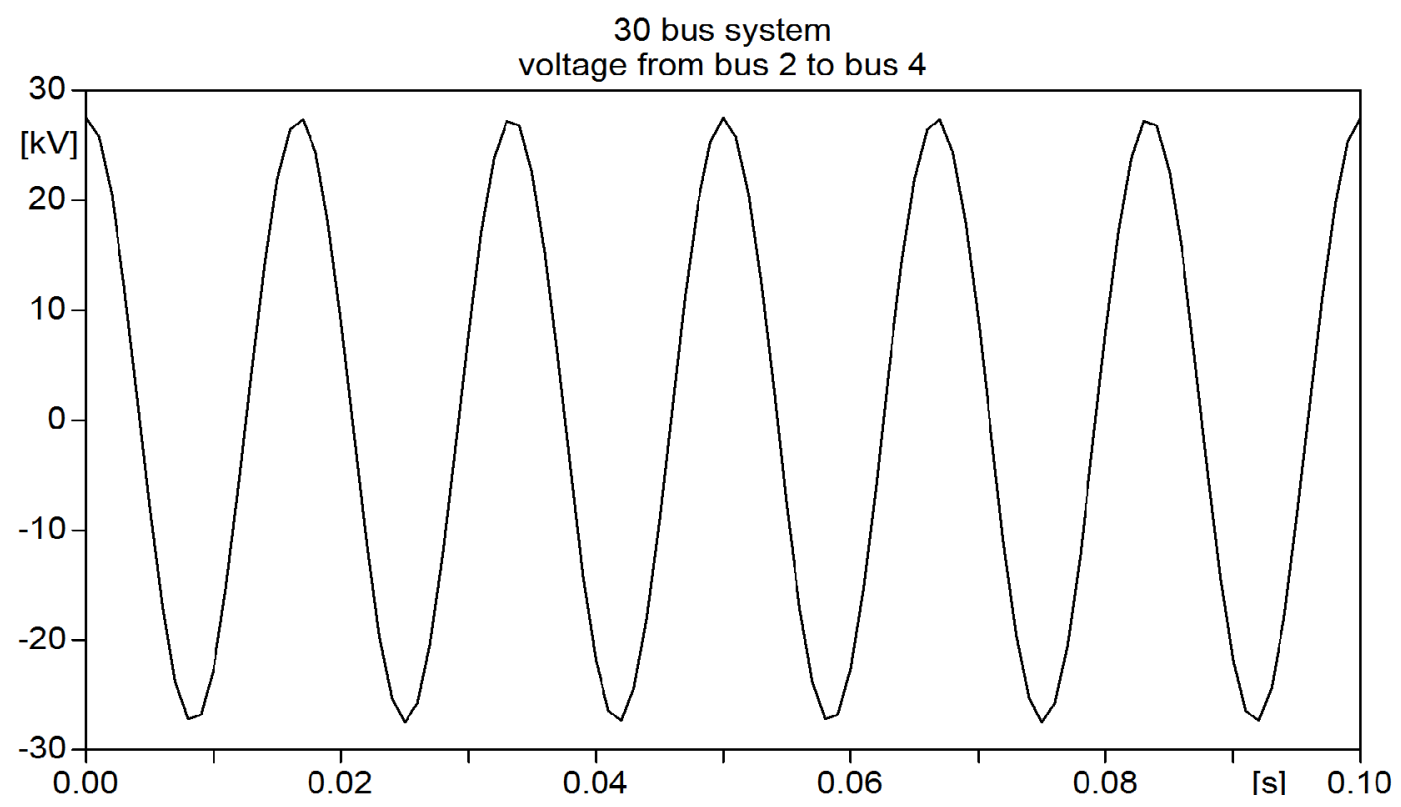

Fig. (21): The voltage from bus 2 to bus 4 without any congestion

Proceedings of the $6^{\text {th }}$ ICEENG Conference, 27-29 May, 2008

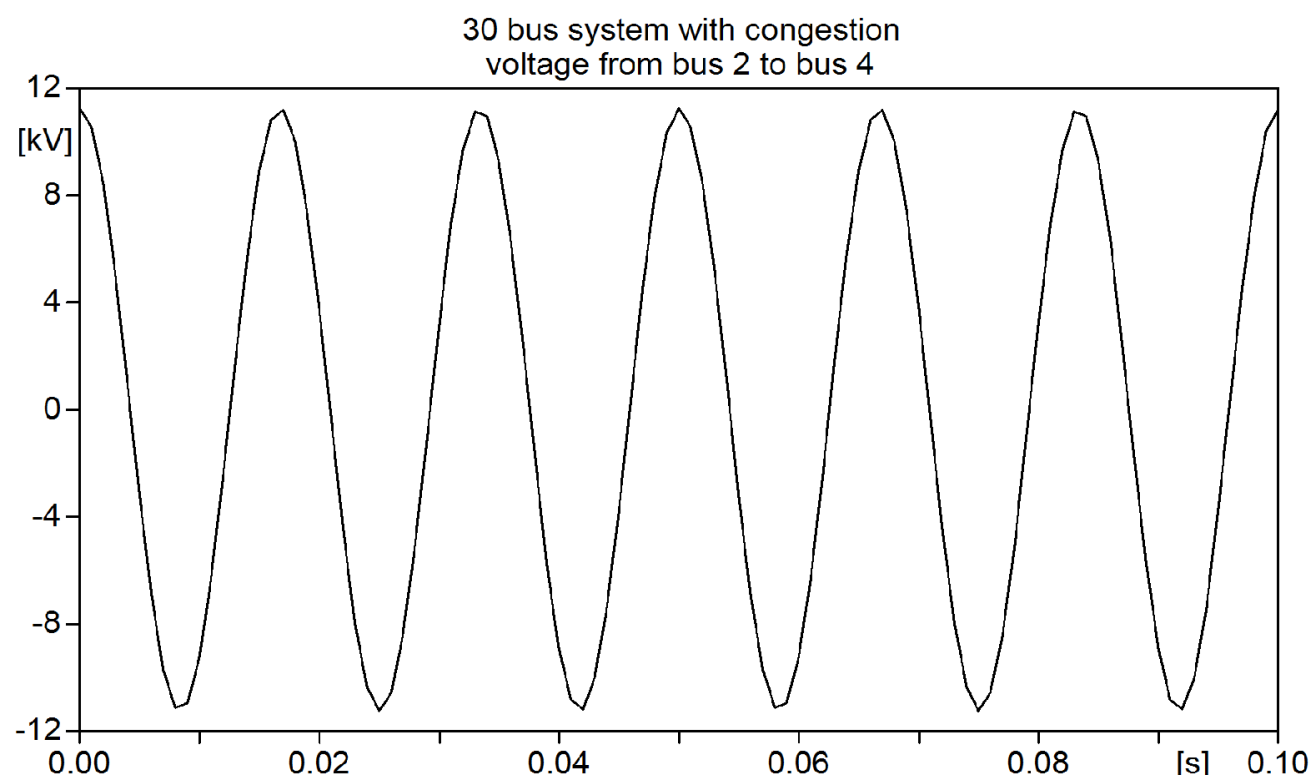

Fig. (22): The voltage from bus 2 to bus 4 with congestion 
Proceedings of the $\boldsymbol{6}^{\text {th }}$ ICEENG Conference, 27-29 May, 2008 EE120-18

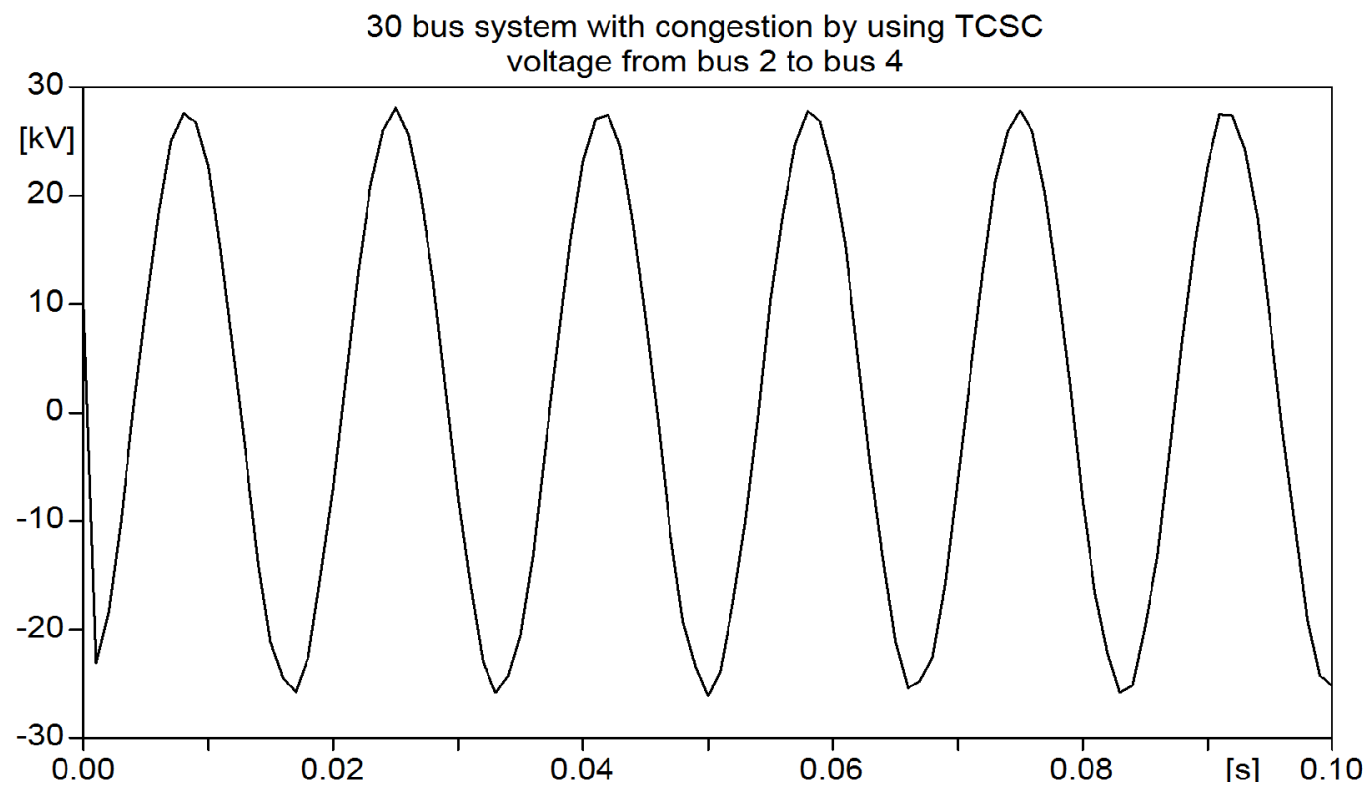

Fig. (23): The voltage from bus 2 to bus 4 with congestion by using (TCSC) at bus 2

Proceedings of the $6^{\text {th }}$ ICEENG Conference, 27-29 May, 2008

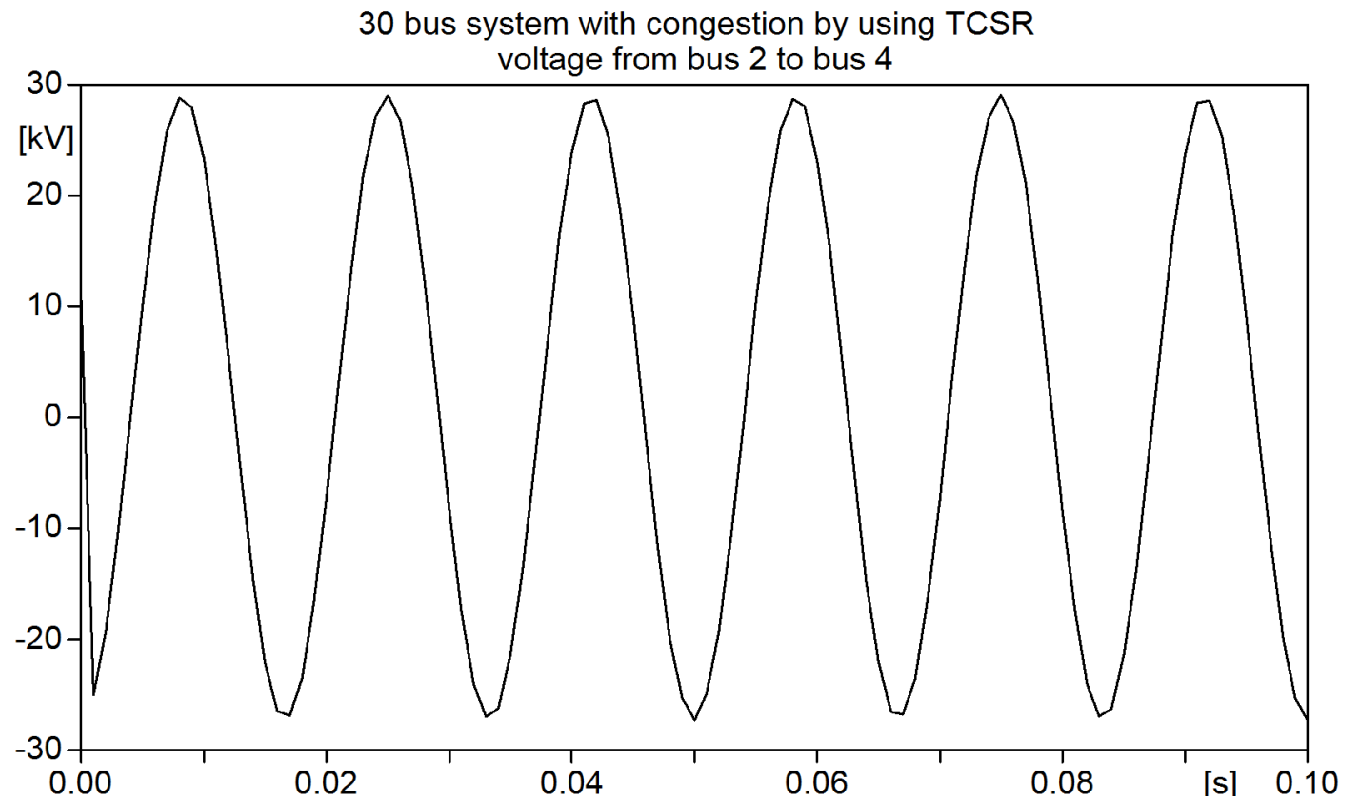


Proceedings of the $\boldsymbol{6}^{\text {th }}$ ICEENG Conference, 27-29 May, 2008 EE120-19

Fig. (24): The voltage from bus 2 to bus 4 with congestion by using (TCSR) at bus 2

\subsubsection{Comments on the results:}

It is shown from Fig. 4-15 and Fig. 17-24 that in case of congestion due to generator faults the voltage between buses has been decreased. By using TCSC at the lines that have been congested, the voltage has increased to the normal state and by using TCSR at the lines that have been congested the voltage has increased very near to the normal state. TCSC is better than TCSR as a FACTS device used to control in the congestion management.

\section{Conclusions:}

In this paper, two FACTS devices, namely TCSC and TCSR are used to study their effect on the optimal congestion management for the IEEE 14 bus power system and the IEEE 30 bus power system. To find the optimal location and rating of these FACTS devices, the ATP simulation program is used for power flow calculation and determination of the lines that have been congested due to generator faults. From the simulation results obtained by using the FACTS devices, voltage in the congestion state has been improved.

Proceedings of the $6^{\text {th }}$ ICEENG Conference, 27-29 May, 2008

18

\section{References:}

[1] Federal Energy Regulatory Commission (FERC), "Regional Transmission Organizations", Washington, DC, Docket RM99-2-000, Order 2000, 20 December 1999.

[2] W.W. Hogan, "Contract Networks for Electric Power Transmission", J. Regul. Econ. 4, pp. 211-242, 1992.

[3] F. D. Galiana and M. Ilic, "A Mathematical Framework for the Analysis Band Management of Power Transactions Under Open Access", IEEE Transactions on Power Systems Vol. 13, No. 2, pp. 681-687, 1998.

[4] R. S. Fang and A.K. David, "Transmission Congestion Management in an Electricity Market", IEEE Transactions on Power Systems Vol. 4, No. 3, pp. 877883, 1999. 
Proceedings of the $\boldsymbol{6}^{\text {th }}$ ICEENG Conference, 27-29 May, 2008 EE120-20

[5] S. C. Srivastava and Perveen Kumar, "Optimal Power Dispatch in Deregulated Market Considering Congestion Management", Proceedings of the Conference on Electric Utility Deregulation and Restructuring and Power Technologies, pp. 5359, City University, London, 4-7 April 2000.

[6] S. N. Singh and A. K. David, "Optimal Location of FACTS Devices for Congestion Management", Int. J. Electric Power System Research Vol. 58, pp. 7179, 2001.

[7] T. Van Cutscm, "A Method to Compute Reactive Power Margins with respect to Voltage Collapse", IEEE Transactions on Power Systems, Vol. 6, No. 1, pp. 145-156, February 1991.

[8] J. Lu, C. W. Liu, and J. S. Thorp, "New Methods for Computing a Saddle-node Bifurcation Point for Voltage Stability Analysis", IEEE Transactions on Power Systems, Vol. 10, No. 2, pp. 978-989, May 1995.

[9] C. J. Park, I. F. Morrison, and D. Sutanto, "Aplication of an Optimization Method for Determining the Teactive Margin from Voltage Collapse in Reactive Power Planning", IEEE Transactions on Power Systems, Vol. 11, No. 3, pp. 1473-1483, August 1996.

[10] C. A. Canizares, "Calculating Optimal System Parameters to Maximize the Distance to Saddle-node Bifurcations", IEEE Transactions on Cicuits and Systems I, May 1997.

[11] R. P. Klump and T. J. Overbye, "A Transmission-based Voltage Stability Measure for Available Transfer Capability (ATC) Calculation", Proc. NAPS, MIT, pp. 351-357, November 1996.

[12] A. R. Bergen, "Power Systems Analysis", Prentice-Hall, New Jersey, 1986.

[13] D. Maratukulam, Proc. FACTS Conference I The Future in High-Voltage Transmission, TR-100504, EPRI, March 1992.

Proceedings of the $6^{\text {th }}$ ICEENG Conference, 27-29 May, 2008 
[14] L. Gyugyi, "Dynamic Compensation of AC Transmission Lines by Solid-State Synchronous Voltage Sources", IEEE Transactions on Power Delivery, Vol. 9, No. 2, pp. 904-911, April 1994.

[15] Y. Mansour, W. Xu, F. Alvarado, and C. Rinzin, "SVC Placement Using Critical Modes of Voltage Instability", IEEE Transactions on Power Systems, Vol. 9, No. 2, pp. 757-763, May 1994.

[16] L. A. S. Pilotto, W. W. Pinr, A. R. Carvalho, A. Wey, W. F. Long, F. L. Alvarado, C. L. DeMarco, and A. Edris, "Determination of Needed Facts Controllers that Increase Asset Utilization of Power Systems", IEEE Transactions on Power Delivery, Vol. 12, No. 1, pp. 364-371, January 1997.

[17] Douglas J. Gotham, "Power Flow Control and Power Flow Studies for Systems with FACTS Devices", IEEE Transactions on Power Systems, Vol. 13, No. 1, Feb. 1998.

\section{Nomenclatures:}

\begin{tabular}{|l|l|}
\hline FACTS & Flexible AC Transmission System \\
\hline TCSCs & Thyristor Controlled Series Capacitors \\
\hline TCSR & Thyristor Controlled Series Reactor \\
\hline TCRs & Thyristor Controlled Reactors \\
\hline VSIs & Voltage Source Inverters \\
\hline SSSCs & Series Static Synchronous Compensators \\
\hline UPFCs & Unified Power Flow Controllers \\
\hline TTC & Total Transfer Capability \\
\hline SVC & Static VAR Compensator \\
\hline ATP & Alternative Transients Program \\
\hline$\alpha$ & Delay Angle \\
\hline$X_{C}$ & Reactance of Reactor \\
\hline$X_{L}$ & Reactance of Series Capacitor \\
\hline$X_{\text {tcsc }}$ & Reactance of TCSC \\
\hline
\end{tabular}

